\title{
Engineering Technology Students' Attitudes towards Engagement in Mathematics
}

\author{
Khairum Hamzah ${ }^{1}$, Najiyah Safwa Khashi' ie ${ }^{1}$, Iskandar Waini ${ }^{1}$, Nurul Amira \\ Zainal $^{1}$, Siti Haryanti Hairol Anuar ${ }^{1}$, Nor Hafizah Hussin ${ }^{1}$ \\ ${ }^{I}$ (Faculty of Engineering Technology, Universiti Teknikal Malaysia Melaka, Malaysia)
}

\begin{abstract}
The objective of this study is to understand and examine the attitudes of Engineering Technology (ET) students towards engagement in mathematics during their studies at the Faculty of Engineering Technology (FTK), Universiti Teknikal Malaysia Melaka (UTeM). In the study, a set of questionnaire that covers the questions on the students' attitudes towards engagement in mathematics was utilized. A total of 332 second year ET students at FTK, UTeM were requested to complete this set of questionnaire during the final week of semester two for 2013/2014 session. From the findings, a conclusion has been drawn regarding the attitudes of the ET students towards engagement in mathematics. The result showed that most of the ET students were very engaged in mathematics, and their engagement was more on behavioral types during the learning process of mathematics in class at FTK, UTeM.
\end{abstract}

Keywords: Attitude, Confidence, Engineering Technology

\section{Introduction}

Nowadays, mathematics is becoming increasingly important in many areas including science, engineering, business and information technology. "There is a global perception that a workforce with a substantial proportion educated in mathematics, engineering and science is essential to future property" [1]. Mathematics also plays a crucial role for Engineering Technology students. Engineering Technology has become an essential goal for many countries where there are great needs for competent technical workforces [2]. The achievement of mathematics is very important in order to achieve this goal. According to [3], ET differs from pure engineering and pure technologies. ET education is more towards applied knowledge compared to engineering degree education, which is more on theoretical science. Students' engagement is very important and plays a crucial role in the learning activities as ET is more applied and hands-on oriented. This study intends to examine and understand students' attitudes among ET students towards mathematics and focus more on students' engagement with the subject itself.

In the process of teaching and learning mathematics, students' attitude towards mathematics is vital, and it can affect students' achievement [4]. Previous research concluded that positive attitudes towards mathematics leads students towards success in mathematics [5],[6],[7]. In order to increase the positive attitudes towards mathematics, three elements that are very related to attitude should be covered. These three elements are students' attitudes towards mathematics confidence, mathematics motivation and mathematics engagement. The focus and objective of this study are to understand and examine ET students' attitudes towards engagement in mathematics during the learning process of mathematics in class at FTK, UTeM. Engagement is very important primarily because of its relationship with academic achievement of learners [8],[9]. This study focuses on engagement in mathematics compared to other elements because engagement is vital in learning process, and it is also one of the key elements in students' attitudes.

According to [10], engagement is defined as students' psychological investment in an effort directed towards learning, understanding or mastering knowledge, skills or crafts that academic work is intended to promote. In addition, there are three dimensions of engagement, which are behavioral, affective and cognitive engagement [11]. According to [12], behavioral engagement is related to students' active participation in learning activities. Behavioral engagement is related to efforts made by students for mathematical tasks and how students relate to each other, and for the lecturer, behavioral engagement is related to their willingness to seek help, attendance at classes and others [13]. [12] highlighted that affective engagement is also known as emotional engagement, where refers to students' attitudes towards activities such as perceived value, interest in and others. The last dimension in engagement is cognitive engagement, which can be seen as psychological investment [11]. According to [14], cognitive engagement is related to students' use of metacognitive and selfregulation strategies. Learning approaches, including deep and surface approaches, are closely related to cognitive engagement [12].

Students' beliefs and attitudes towards mathematics in teaching and learning is an integral part of mathematics education [15]. Students' learning outcomes are strongly related to their attitudes towards mathematics. As mentioned previously, there are three main elements in attitudes towards mathematics. 
Therefore, the objective of this study is to understand and examine ET students' attitudes towards mathematics engagement during studies at FTK, UTeM, which focuses on one of the three main elements of attitudes.

\section{Methodology}

A questionnaire from a previous study by [16] was applied to collect primary data. The questionnaires were distributed to 332 second year ET students who specialized in various fields of studies at FTK, UTeM as the target sample. Questions in the questionnaires are more focused on ET students' attitudes towards engagement in mathematics during their class session at FTK, UTeM. The survey was conducted by the authors during the final week of the semester. The results were then analyzed using Microsoft Excel to obtain the statistics for each question.

\section{Results And Discussion}

Table 1 below shows the descriptive statistics of ET students' attitudes towards engagement in mathematics.

Table 1: Students' Attitudes towards Engagement in Mathematics

\begin{tabular}{|c|c|c|}
\hline \multirow{2}{*}{ Statement } & \multicolumn{2}{|c|}{ Percentage $(\%)$} \\
\hline & Agree & Disagree \\
\hline I prefer to work with symbols (algebra) than with pictures (diagram and graph) & 71 & 29 \\
\hline I prefer to work on my own than in a group & 52 & 48 \\
\hline I find working through examples is less effective than memorizing given materials & 59 & 41 \\
\hline I find it helpful to test understanding by attempting exercises and problems & 89 & 11 \\
\hline When studying mathematics, I try to link new ideas or knowledge I already have & 81 & 19 \\
\hline When learning new mathematical materials, I make notes to help me understand and remember & 87 & 13 \\
\hline I like to revise topics all at once rather than space out my study & 75 & 25 \\
\hline I do not usually make time to check my own working, find and correct errors & 71 & 29 \\
\hline
\end{tabular}

The objective of this study is to understand and examine ET students' attitudes towards engagement in mathematics during their class session at FTK, UTeM. As mentioned previously, there are three dimensions of engagement, which are behavioral, affective and cognitive engagement. As shown in Table 1 above, most of the ET students' at FTK, UTeM was more towards behavioral engagement. 298 out of 332 respondents, which is $89 \%$, agreed with the statement that they find it helpful to test understanding by attempting exercises and problems. ET students' believed that in order to success in mathematics, they should be more active by doing a lot of exercises and solve problems on mathematics. Active participation in the study is the most important criterion for behavioral engagement. ET students' were also active in making notes when they learnt new things in mathematics. This can be shown by $87 \%$ of the respondents agreed with the statement that when they are learning new materials in mathematics, they make notes to help them in understanding and remembering.

271 out of 332 respondents, which is $81 \%$, agreed with the statement that when they study mathematics, they try to link new ideas or knowledge that they already have. This statement also shows that ET students' are very active and at the same time, they applied a deep approach of learning, which is much related to cognitive engagement as discussed previously.

Generally, most of the respondents, as shown in Table 1 above, have engagement in mathematics based on their attitudes during their studies at FTK, UTeM. However, the types of engagement are important rules in order to success in mathematics, which is suitable with their fields of study. Most of ET students' preferred to work on their own compared to in a group. However, the percentage that agreed with this statement was only $52 \%$, and this was the lowest percentage that was agreed by the respondents. Hence, it can be said that ET students' have mixed attitudes in their ways of studies.

\section{Conclusion}

Students' attitudes towards mathematics play a crucial role in the teaching and learning processes of mathematics. It affects students' achievement in mathematics. Engagement in mathematics is one of the main ideas to understand students' attitudes towards mathematics. The level of students' engagement towards mathematics can give a big effect on their results. There are several types of engagement, which include behavioral, affective and cognitive engagement as discussed previously. The main objective of this study is to understand and examine ET students' attitudes towards engagement in mathematics during their class session at FTK, UTeM. From this study, it can be concluded that most of the ET students are very engaged and more towards behavioral engagement, where students participate actively in learning activities, especially 
mathematics. It is suitable for ET students that are more focused in hands-on part during learning activities, and students also give full concentration and become active students.

Overall, the results of this study supported the researcher's claims and findings. However, the results of this study need to be interpreted in relative to the limitations of the study. The external validity is compromised by the small sample size; hence, the findings of this study have limited generalizability. In the future, larger samples should be collected where ET students from other year of study should be included, so that a proper conclusion may be derived for all ET students as the population sample.

\section{References}

[1] I. Chubb, Mathematics, engineering and science in the national interest, Retrieved from http://www.chiefscientist.gov.au/wpcontent/uploads/Office-of-the-Chief-Scientist-MES, 2012.

[2] M.S. Yahaya, A. Noordin, S. Ahmad and M.R. Sapiee, Engineering technology program in Malaysia: A market survey, Proc. International Conference on Teaching and Learning in Higher Education, Johor, Malaysia, 2012.

[3] A. Sayuthi, Z. Jano, N. hashim, S. Ahmad and R. Abdullah, The implementation of PBL in physics for engineering technology courses: A case study for faculty of engineering technology, Universiti Teknikal Malaysia, Proc. International Conference on Teaching and Learning in Higher Education, Johor, Malaysia, 2012.

[4] M.S. Farooq and S.Z.U. Shah, Students' attitude towards mathematics, Pakistan Economic and Social Review, 46(1), $2008,75-83$.

[5] A.C. Barton, Crafting multicultural science education with pre-service teachers through service-learning, Journal of Curriculum Studies, 32(6), 2000, 797-820.

[6] F. Furinghetti and E. Pehkonen, Beliefs: A hidden variable in mathematics education?(Kluwer Academic Publishers, 2002).

[7] X. Ma and J. Xu, Assessing the relationship between attitude towards mathematics and achievement in mathematics: A metaanalysis, Journal for Research in Mathematics Education, 28(1), 2004, 26-47.

[8] P.L. Peterson and E. Fennema, Effective teaching, student engagement in classroom activities, and sex-related differences in learning mathematics, American Educational Research Journal, 22(3), 1985, 309-335.

[9] S.Y. Park, Student engagement and classroom variables in improving mathematics achievement. Asia Pacific Education Review, 6(1), 2005, 87-97.

[10] F.M. Newmann, G.G. Wehlage and S.D. Lamborn, Student engagement and achievement in American secondary school (New York, Teachers College Press, 1992).

[11] J.A. Fredericks, P.C. Blumenfeld and A.H. Paris, School engagement: Potential of the concept, state of the evidence, Review of Educational Research, 74(1), 2004, 59-109.

[12] Q.P. Kong, N.Y. Wong and C.C. Lam, Student engagement in mathematics: Development of instrument and validation of construct, Mathematics Educational Research Journal, 15(1), 2003, 4-21.

[13] E.A. Linnenbrink and P.R. Pintrich, The role of self-efficacy beliefs in student engagement and learning in classroom, Retrived from http://www.informaworld.com/smpp/content $\sim$ content $=\mathrm{a} 713845294 \sim \mathrm{db}=\mathrm{all} \sim$ order=page, 2008.

[14] J.L. Meece, P.C. Blumenfeld and R.H. Hoyle, Students' goal orientations and cognitive engagement in classroom activities, Journal of Educational Psychology, 80(4), 1988, 514-523.

[15] D.B. McLeod, Affect and mathematical problem solving: A new perspective (New York, Springer-Verlag, 1989).

[16] P. Galbraith and C. Haines, Disentangling the nexus: Attitudes to mathematics and technology in a computer learning environment, Educational Studies in Mathematics, 36, 1998, 275-290. 